\title{
Effects of DLC/TiAIN-coated die on friction and wear in sheet-metal forming under dry and oil-lubricated conditions: Experimental and numerical studies
}

\author{
Sulaiman, M. H.; Farahana, R. N.; Bienk, K.; Nielsen, C. V.; Bay, N.
}

Published in:

Wear

Link to article, DOI:

10.1016/j.wear.2019.203040

Publication date:

2019

Document Version

Peer reviewed version

Link back to DTU Orbit

Citation (APA):

Sulaiman, M. H., Farahana, R. N., Bienk, K., Nielsen, C. V., \& Bay, N. (2019). Effects of DLC/TiAIN-coated die on friction and wear in sheet-metal forming under dry and oil-lubricated conditions: Experimental and numerical studies. Wear, 438-439, [203040]. https://doi.org/10.1016/j.wear.2019.203040

\section{General rights}

Copyright and moral rights for the publications made accessible in the public portal are retained by the authors and/or other copyright owners and it is a condition of accessing publications that users recognise and abide by the legal requirements associated with these rights.

- Users may download and print one copy of any publication from the public portal for the purpose of private study or research.

- You may not further distribute the material or use it for any profit-making activity or commercial gain

- You may freely distribute the URL identifying the publication in the public portal 


\section{Journal Pre-proof}

Effects of DLC/TiAIN-coated die on friction and wear in sheet-metal forming under dry and oil-lubricated conditions: Experimental and numerical studies

M.H. Sulaiman, R.N. Farahana, K. Bienk, C.V. Nielsen, N. Bay

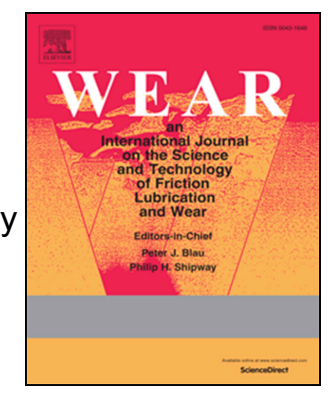

PII: $\quad$ S0043-1648(19)30357-6

DOI: $\quad$ https://doi.org/10.1016/j.wear.2019.203040

Reference: WEA 203040

To appear in: Wear

Received Date: 16 February 2019

Revised Date: 1 September 2019

Accepted Date: 1 September 2019

Please cite this article as: M.H. Sulaiman, R.N. Farahana, K. Bienk, C.V. Nielsen, N. Bay, Effects of DLC/TiAIN-coated die on friction and wear in sheet-metal forming under dry and oil-lubricated conditions: Experimental and numerical studies, Wear (2019), doi: https://doi.org/10.1016/ j.wear.2019.203040.

This is a PDF file of an article that has undergone enhancements after acceptance, such as the addition of a cover page and metadata, and formatting for readability, but it is not yet the definitive version of record. This version will undergo additional copyediting, typesetting and review before it is published in its final form, but we are providing this version to give early visibility of the article. Please note that, during the production process, errors may be discovered which could affect the content, and all legal disclaimers that apply to the journal pertain.

(C) 2019 Published by Elsevier B.V. 


\section{Graphical abstract:}
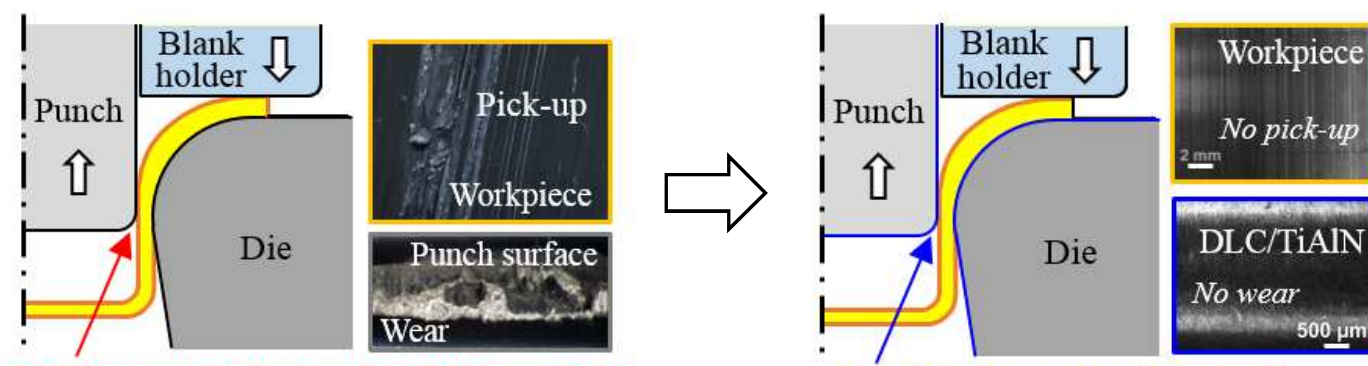

Galling occurs between the sliding surfaces

DLC/TiAlN coating increased die/punch wear resistance
DLC/TiAIN

No wear

a $500 \mu$ 


\title{
Title:
}

Effects of DLC/TiAlN-coated die on friction and wear in sheet-metal forming under dry and oil-lubricated conditions: Experimental and numerical studies

M.H. Sulaiman ${ }^{\mathrm{a}, *}$, R.N. Farahana ${ }^{\mathrm{a}}$, K. Bienk ${ }^{\mathrm{b}}$, C.V. Nielsen ${ }^{\mathrm{c}}$, N. Bay ${ }^{\mathrm{c}}$

a School of Mechatronic Engineering, Universiti Malaysia Perlis, 02600 Arau, Perlis, Malaysia

${ }^{\mathrm{b}}$ CemeCon Scandinavia A/S, Navervej 28, 8382 Hinnerup, Denmark

${ }^{c}$ Department of Mechanical Engineering, Technical University of Denmark, 2800 Kongens Lyngby, Denmark

*E-mail: hafissulaiman@unimap.edu.my

\begin{abstract}
$^{1}$
Experimental and numerical analyses were conducted to explore the influence of DLC/TiAlN-coated die surfaces in sheet-metal forming under dry and oil-lubricated conditions. In this study, ironing and deep-drawing experiments were performed to determine the potential of the DLC/TiAlN coating in the sheet forming of stainless steels under different tribological conditions. The performance and physical properties of the DLC/TiAlN-coated die surface were obtained through load, surface roughness, and wear measurements as well as hardness and microstructure examination. The experimental results indicated that the DLC/TiAlN coating strongly resists galling under dry friction and thin film lubrication conditions that reduces the friction and forming load. The presence of a thin oil film reduces the sliding-originated surface tensile stresses of the DLC/TiAlN coating, improving the wear resistance of the die surface even at high temperatures and high contact pressures. Thermomechanical numerical analysis supported the experimental results, which confirmed that the lubricant discharged the heat generated in the die-workpiece contact region to reduce the friction and forming load. With the DLC/TiAlN coating, the plain mineral oil with no extreme pressure additives can function as effective as chlorinated paraffin oil for protecting the die surface, thus extending the die service life.
\end{abstract}

\section{Keywords}

\footnotetext{
1 Abbreviations: DLC, diamond-like carbon; FEM, finite-element method; LOM, light optical microscope; PVD, physical vapor deposition.
} 
Sliding wear; Sliding friction; Galling; Steel; Carbon-based coatings; Other manufacturing processes.

\section{Introduction}

Poor surface finish and production downtime are challenging issues in sheet-metal forming. They are commonly caused by problems related to insufficient lubrication systems between the two die-workpiece sliding surfaces, which frequently cause the breakdown of the lubricant film. The lubricant-film breakdown causes direct metal-to-metal contact between the two sliding surfaces, resulting in the negative effects of metal-to-metal transfer between the two contacting surfaces, as well as die wear and galling. As preventive measures for these issues, good boundary lubricants, such as chlorinated paraffin oils and die surface treatments, are commonly applied in industry $[1,2]$. Because the majority of the available commercial boundary lubricants are hazardous to human health and the environment, European countries and Japan have approved and enforced legislation to disallow the utilization of these hazardous lubricants in industrial applications [3]. These are the primary challenges faced by industry, particularly for reducing production costs and downtime. Antiseizure tool steel can be used as a preventive measure; however, it is expensive and not a suitable choice because it is difficult to machine and shape.

Wear can be defined as damage to the die surface, which involves a progressive loss of workpiece material to the die surface because of the relative motion between the contacting surfaces of the workpiece and the forming die. Generally, the application of good boundary lubricants containing special additives, such as extreme-pressure additives and hard coatings, could increase the wear resistance of the die-workpiece contact surfaces. The combined uses of the good boundary lubricants and hard coatings reduces the friction coefficient and the heat generated at the die-workpiece contact surfaces [4][5]. The decrease in friction caused by these good boundary lubricants and hard coatings reduces the tendency for wear for two possible reasons. First, the coating acts as a heat barrier because its thermal conductivity is lower than that of the substrate. Thus, the proportion of frictional heat that dissipates into the substrate decreases, reducing the substrate temperature [6]. Second, the lubricant separates and cools the workpiece and die surfaces, facilitating sliding phenomena; thus, the tool loads and wear are reduced, and the pick-up and transfer of workpiece material on the die surface is avoided.

A good adhesion strength to the substrate material and a high hardness of the applied coatings is not sufficient to reduce effectively the die wear and galling, if the coating has a 
high tendency towards adhesion with the counter material [7]. Typically, nitride and carbide based coatings, such as titanium nitride $(\mathrm{TiN})$ and chromium nitride $(\mathrm{CrN})$, can provide good wear protection and are most frequently employed in the production of sheet components [8]. However, these are only applicable to sheet forming of soft metal materials, such as $\mathrm{Al}$ and mild steel. The titanium aluminum nitride (TiAlN) coating has been increasingly utilized as a protective layer for cutting and forming dies, in addition to other applications $[9,10]$, as an alternative to other industrial physical vapor deposition (PVD) hard coatings, such as aluminum chromium $(\mathrm{AlCrN})$, titanium carbide $(\mathrm{TiC})$, and titanium chromium nitride ( $\mathrm{TiCN})$ [6]. This is because of its excellent wear resistance and superior performance under hightemperature conditions. However, the friction coefficient of TiAlN is high, especially under dry conditions, achieving $0.9-1.0$ at room temperature and 1.5 at $400^{\circ} \mathrm{C}$ [11]. The TiAlN coating possesses high chemical stability, low thermal conductivity, and high wear resistance at $900^{\circ} \mathrm{C}$ [12]. This is because of the element, $\mathrm{Al}$, incorporated in the TiAlN coating, which forms the superficial $\mathrm{Al}_{2} \mathrm{O}_{3}$ layer for improving the wear resistance and enhancing the chemical stability $[13,14]$. The TiAlN coating also possesses better tribological properties than those of TiN, AlTiN, and CrAlN coatings [8]. The TiAlN coating surface hardness is approximately 3,400-3,600 $\mathrm{Hv}$, producing a high resistance of the TiAlN coating to abrasive wear [15], which renders the TiAlN coating suitable for metal-cutting applications. TiAlNcoated dies have been used for machining hard metals, such as Inconnel718 [16], AISI 141 steel [17], AISI 4340 hardened steel [18], and the Ti alloy, Ti6Al4V [19].

Diamond-like carbon (DLC) coatings have achieved acceptance in various industries, such as the automotive, medical, and tooling components industries, owing to several attractive properties, including a low friction coefficient, high hardness, good wear resistance, and protection of the die surface. These properties render DLC coatings suitable for numerous tribological applications in mechanical systems, such as valve train tappets, gears, and piston pins [20,21]. Multilayered coatings are preferred over single-layered coatings for enhancing the performance [22-24]. The properties of multilayer coatings are superior to those of monolayer coatings, as multilayer ones can combine the properties of the individual layers [25]. Combining the high strength and ductility of substrates with the various excellent properties of coatings, such as high hardness, good oxidation, and wear resistance, coated cemented carbide inserts are widely used for high-speed and high-precision automatic machining [26,27]. Both hard and self-lubricating multilayered coatings can be prepared by selecting appropriate combinations, including multilayered TiAlN/VN, TiAlN/WC, and TiAlN/MoN [28-30]. Additionally, it has been reported that introducing a TiAlN interlayer 
coating between an aC:H DLC coating and the tool steel substrate has improved wear resistance and produced low friction to prevent galling [31]. The high content of $\mathrm{Al}$ in the TiAlN coating results in high hardness, reducing the wear and extending the die lifetime for improved productivity [32].

The objectives of the present study were to evaluate the tribological characteristics of the DLC/TiAlN coatings in sheet-metal forming under dry and oil-lubricated conditions and to compare these characteristics with those of other DLC coatings. For achieving these objectives, a strip-reduction test was performed to imitate the ironing process; additionally, a strip-bending test was performed to imitate the deep-drawing process, as shown in Figure 1. Through these tests, promising coating candidates for severe tribological conditions were identified. Worn die surfaces and microstructure of the DLC/TiAlN coating were also studied. A numerical simulation coupling mechanical and thermal analyses were performed to evaluate the effects of material deformation and heat generation on the friction at the dieworkpiece interface.

\section{Material and methods}

A strip-reduction test replicating an ironing process and a strip-bending test emulating a deep-drawing test were performed to identify the most promising protective coating for reducing the friction and mitigating the wear in sheet-metal forming under dry and oillubricated conditions, see Figure 1. The process conditions used in stainless steel forming production were adopted as a reference case to study accurately the die-workpiece contact surface phenomena. Both of the experimental set-ups used in the present study offered multiple runs of forming processes from a stainless-steel coil to simulate accurately the industrial sheet-metal forming conditions.

The die material was a powder metallurgical cold work tool steel (Vanadis 4) with high $\mathrm{C}$ and $\mathrm{Cr}$ contents that was alloyed with $\mathrm{Mn}, \mathrm{Mo}, \mathrm{Si}$, and $\mathrm{V}$. The dies were throughhardened, tempered to $62 \mathrm{HRC}$, and subsequently polished to a mirror-like surface $(R a=0.02$ $\mu \mathrm{m})$ before the coating was applied. Table 1 presents the mechanical properties and the compositions of the test materials used in the experiments. A plane strain compression test was performed on the stainless steel (AISI 304L) used in the experiments; the results provide the best fitting to the flow stress, $\sigma_{f}$, according to Voce's material model, as shown in Equation 1 and Figure 2. Mineral oils were selected for the experiments. Two of these, with low and high viscosity, respectively, contained no extreme pressure (EP) additives. The last 
one was a mixture of these high and low viscosity oils, producing one with a moderate viscosity. Data on the test lubricants are tabulated in Table 2.

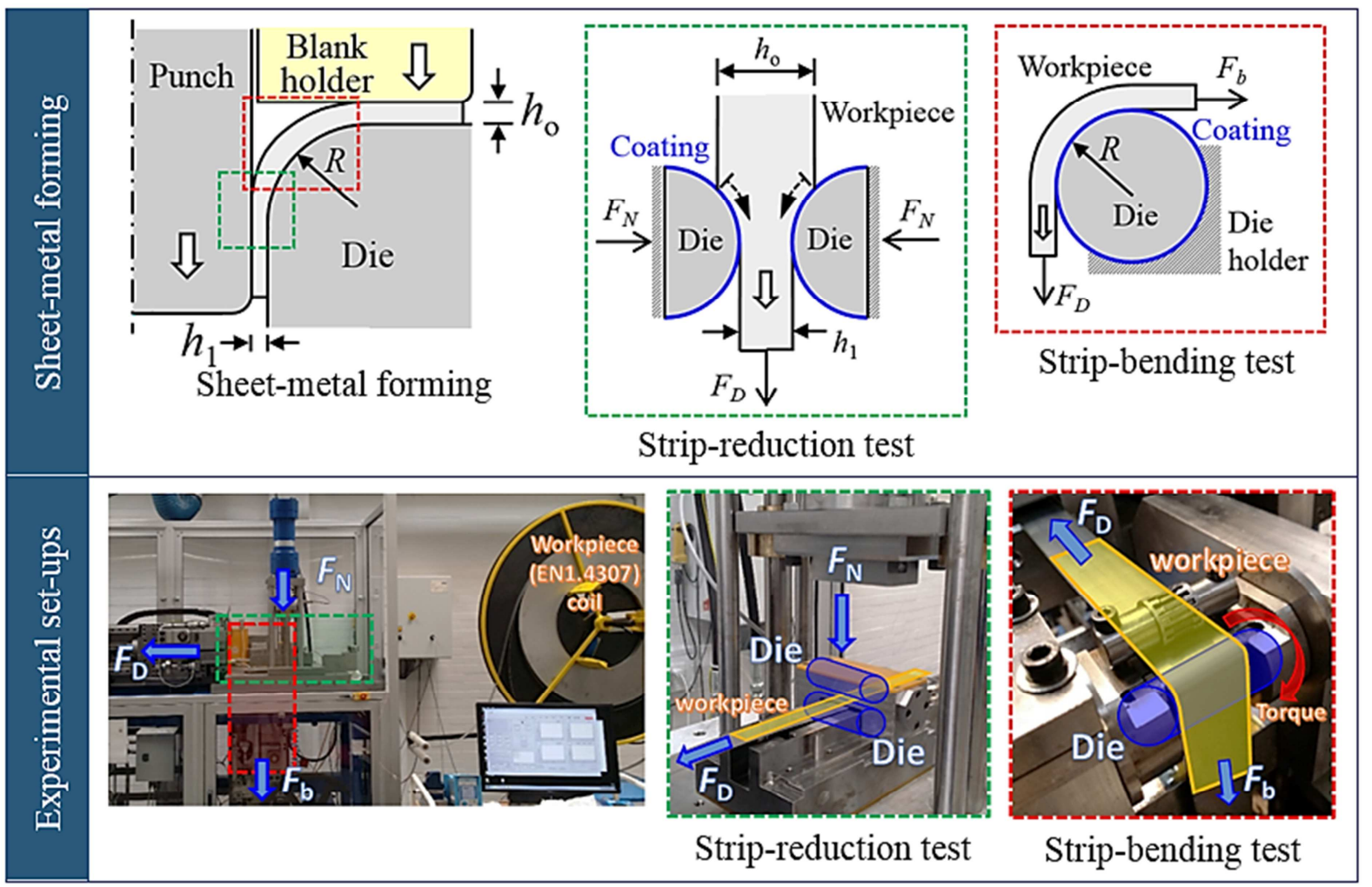

Figure 1: Schematics of the simulative laboratory tests emulating sheet-metal forming.

Table 1: Compositions and mechanical properties of the test materials [33,34].

\begin{tabular}{lcccc}
\hline & & \multicolumn{3}{c}{ Mechanical Properties } \\
\cline { 3 - 5 } Components & Composition (wt. \%) & $\begin{array}{c}\text { Density } \rho \\
\left(\mathrm{g} / \mathrm{cm}^{3}\right)\end{array}$ & $\begin{array}{c}\text { Poisson } \\
\text { ratio } v\end{array}$ & $E(\mathrm{GPa})$ \\
\hline Die & $1.4 \% \mathrm{C}, 0.4 \% \mathrm{Si}, 0.4 \% \mathrm{Mn}$, & 7.56 & 0.3 & 200 \\
(Vanadis 4) & $4.7 \% \mathrm{Cr}, 3.5 \% \mathrm{Mo}, 3.7 \% \mathrm{~V}$ & & & 200 \\
Workpiece & $0.02 \% \mathrm{C}, 18.1 \% \mathrm{Cr}, 8.1 \% \mathrm{Ni}$ & 7.90 & 0.3 & \\
(AISI 304L) & & & & \\
\hline
\end{tabular}

Table 2: Test lubricants applied in the experiments.

\begin{tabular}{ccc}
\hline Lubricant type & Product name & Kinematic viscosity $\eta @ 40^{\circ} \mathrm{C}$ \\
\hline Naphthenic mineral oil & CR5-Sun 60 & $60 \mathrm{cSt}$ [35] \\
Naphthenic mineral oil & Houghton Plunger CR5 & $660 \mathrm{cSt}$ [36]
\end{tabular}




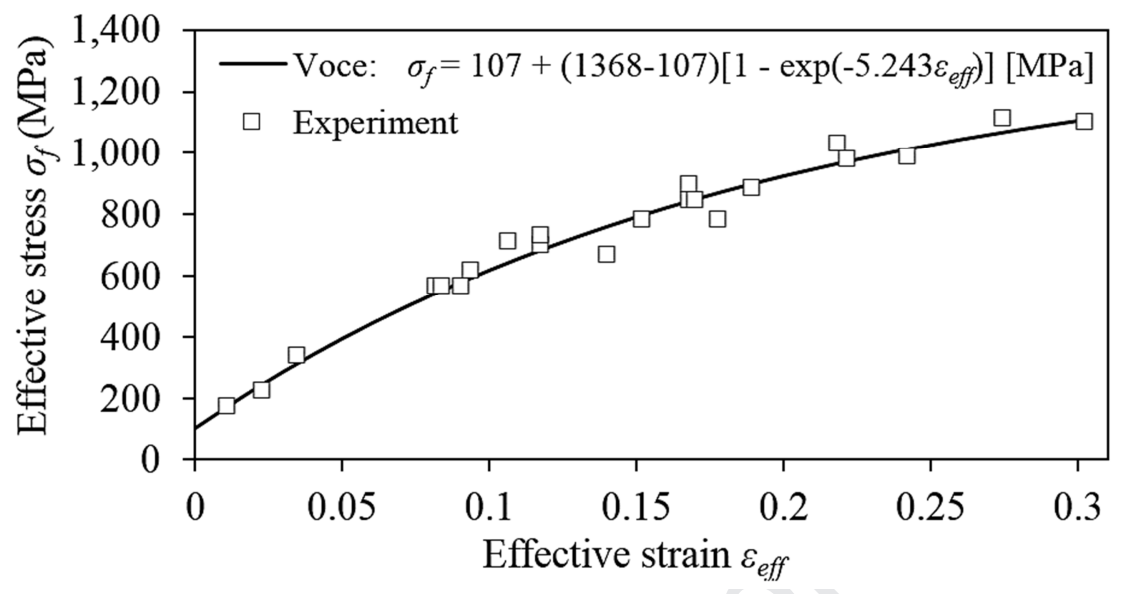

Figure 2: Voce flow curve expression with the measured effective stress-strain values for the plane strain compression of the stainless steel AISI 304L sheet.

$$
\sigma_{f}=107+(1368-107)\left[1-\exp \left(-5.243 \varepsilon_{e f f}\right)\right][\mathrm{MPa}]
$$

(Equation 1)

\subsection{Coatings}

Three DLC coatings were studied; their performances were compared with those of the TiAlN coating and uncoated samples. Single-layer TiAlN, single-layer DLC, double-layer DLC/TiAlN, and multilayer DLC coating films were each deposited onto the tool steel substrates (Vanadis 4, with a surface hardness of 62 HRC), as described in Figure 3. The die roughness after coating was identical to that before: $R a=0.02 \mu \mathrm{m}$. These test coatings were deposited via a PVD process based on unbalanced magnetron sputtering. The mechanical properties and surface characteristics of the test coatings are presented in Table 3, where the uncertainty values represent three-to-five times that of the observed variations in the investigated areas. Figure 3(a) and Figure 3(b) show that the single-layer TiAlN and DLC comprise a gradient amorphous carbon hydrogen $(\mathrm{aC}: \mathrm{H})$ DLC coating structure deposited directly onto the Vanadis 4 tool steel, respectively. Figure 3(c) shows the a:C-H DLC supported by two other coating films, $\mathrm{CrN}$ and $\mathrm{CrCN}$, which act as bonding layers that are deposited onto the TiAlN-coated die surface. Nano-layer DLC coating films were deposited onto the same Vanadis 4 die surface, as shown in Figure 3(d). Coating binders, $\mathrm{CrN}$, and $\mathrm{Cr}$ interlayer coatings were added to the DLC coating in the form of a gradient coating structure. 

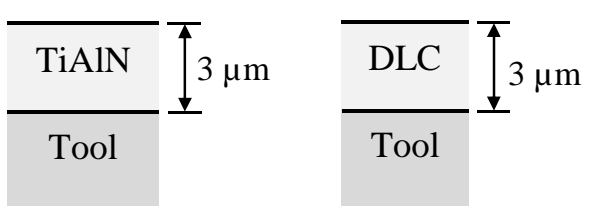

a) TiAlN

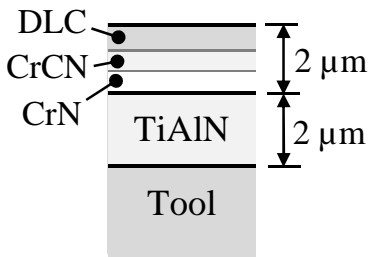

c) DLC/TiAlN

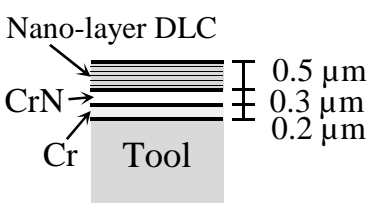

d) Multilayer DLC

Figure 3: Four different types of hard coatings were deposited on the tool steel Vanadis 4: a) single-layer TiAlN, b) single-layer DLC, c) double-layer DLC/TiAlN, and d) multilayer DLC.

Table 3: Mechanical properties and surface characteristics of the coatings.

\begin{tabular}{lccc}
\hline Coatings & Thickness $(\mu \mathrm{m})$ & Hardness $(\mathrm{HV})$ & Roughness $R a(\mu \mathrm{m})$ \\
\hline TiAlN & $3 \pm 0.20$ & 3,700 & 0.021 \\
DLC & $3 \pm 0.20$ & 2,800 & 0.043 \\
DLC/TiAlN & $4 \pm 0.40$ & 3,000 & 0.026 \\
Nano-multilayer DLC & $1 \pm 0.05$ & 2,700 & 0.036 \\
\hline
\end{tabular}

\subsection{Characterization of coatings}

The surface roughness was measured using a tactile roughness profilometer (Taylor Hobson Form TalySurf Series 2 50i). A light optical microscope (LOM) was used to detect the material transfer to the die surface in the contact region. Scanning electron microscopy combined with energy-dispersive X-ray spectroscopy (SEM-EDX) was utilized to investigate the elements of the wear scar on the coated die surface after the experiments. Prior to the investigation, all the worn surfaces were cleaned via repeated immersion in an acetone bath. A cross-sectional morphological analysis of the DLC/TiAlN coating was performed to obtain structural information about the DLC/TiAlN coating.

\section{Results and discussion}

\subsection{Coated die performance in forming of stainless steels}

\subsubsection{Strip-reduction of stainless steels with DLC-and TiAlN-coated die surfaces}

Figure 4(a) shows the effects of the die temperature and the lubrication condition on the forming load in the strip-reduction test. The experimental results plotted were based on an 
average of five repetitions. The dies were deposited with four different coatings, as shown in Figure 3. A non-coated die was used as a reference case. The results refer to both lubricated and dry conditions. The effect of the die temperature at room temperature $\left(20^{\circ} \mathrm{C}\right)$ and an elevated temperature of $80^{\circ} \mathrm{C}$ were comprehensively studied. As predicted, the non-coated die suffered from adhesive wear under both the lubricated and dry conditions. An increased die temperature caused more severe wear on the die surface. Figure 4(a) shows a small load was observed for the DLC/TiAlN-coated dies under all test conditions. Meanwhile, a high load was observed for the other coatings in the strip-reduction of austenitic stainless steel, AISI 304L, under dry friction condition, indicating that the other coatings failed to function properly without the presence of a thin lubricant film. Figure 4(b) shows the effects of the die temperature and the lubrication condition on the workpiece surface finish in the stripreduction test. The workpiece roughness $R a$ values were measured based on an average of at least six measurements. A reasonably good surface finish of the formed sheet, with almost no scratches, was observed for the DLC/TiAlN-coated die under all the test conditions. The DLC/TiAlN die was the only one that could withstand the severe test conditions at room temperature and the elevated temperature, as indicated by the low surface roughness, $R a$, since a high surface roughness, $R a$, value indicates that the die surface experienced severe wear. The results indicate that the DLC/TiAlN coating has good adhesion strength and can prevent wear in dry and lubricated conditions, as indicated by the small formed sheet roughness value. The experiments indicated that other coatings, such as TiAlN, single-layer DLC, and multilayer DLC, are capable of preventing wear under lubricated conditions only, as they suffered severe wear on the die surface under dry lubrication conditions, as evidenced by the large formed sheet roughness $(R a>1 \mu \mathrm{m})$ and the LOM images of the formed sheet and the die surfaces. Figure 5 shows the effects of the high temperature of $80{ }^{\circ} \mathrm{C}$ and the dry friction condition on the workpiece surface finish and die wear in the strip-reduction test. For all the die surfaces tested, the adhesive wear was detected by LOM images to be the primary cause of wear on the coated die surfaces. This is because soft workpiece material was visibly transferred onto the hard-coated die surface, causing the galling to occur. These screening test results indicate that DLC/TiAlN was superior under all test and lubrication conditions, as it forms a strong protective coating film that can reduce the forming load as well as withstand a high contact pressure and a high interface temperature. This explains why the DLC/TiAlN coating strongly resists galling under dry friction and thin film lubrication conditions, in which the other coatings can only function with the presence of a thin oil film. 


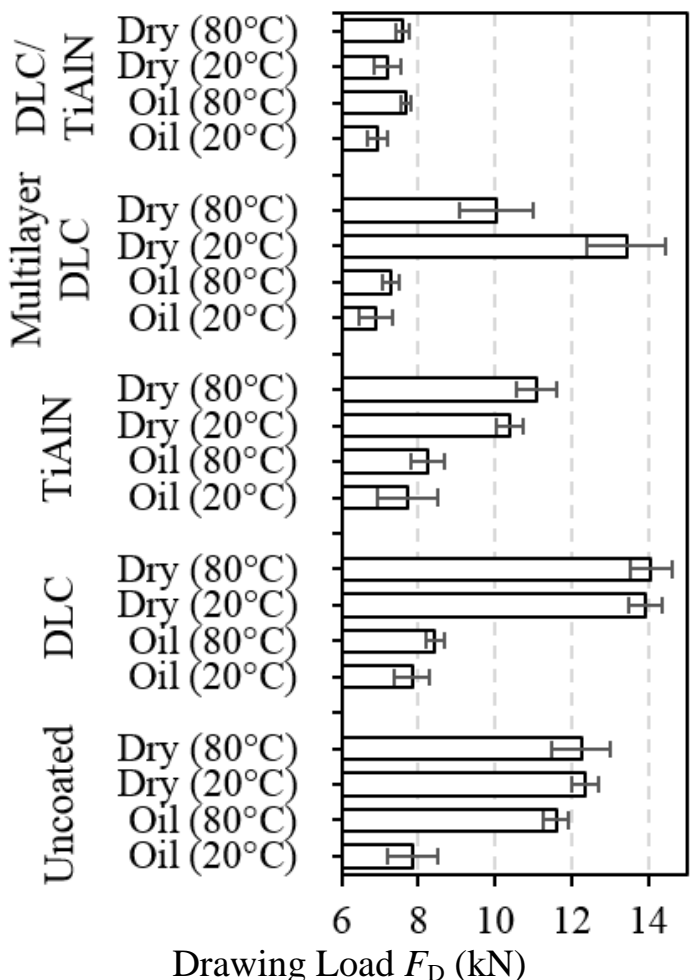

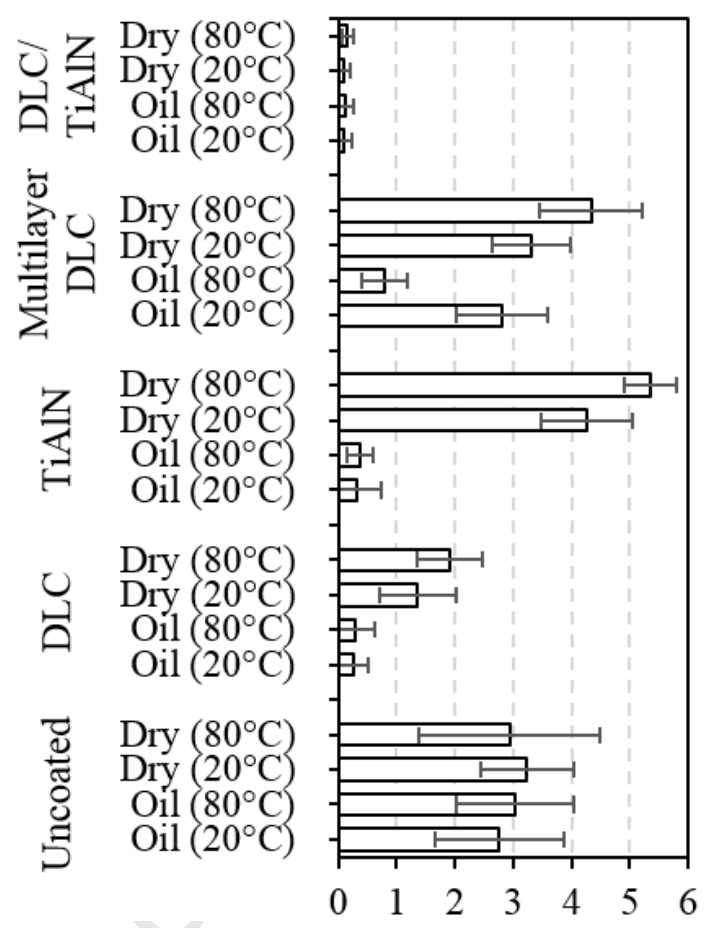

Workpiece Roughness $R a(\mu \mathrm{m})$

\begin{tabular}{|ll|}
\hline Test parameters used in one-time strip-reduction test: \\
Workpiece $=$ AISI $304 \mathrm{~L}, w 15 \times t 1 \mathrm{~mm}^{2}$ & Sliding length $L=300 \mathrm{~mm}$ \\
Die diameter $\emptyset_{\text {die }}=15 \mathrm{~mm}$ & Thickness reduction $\Delta t=15 \%$ \\
Sliding speed $v=65 \mathrm{~mm} / \mathrm{s}$ & CR5-Sun 60 oil $\eta=60 \mathrm{cSt}$ \\
\hline
\end{tabular}

Figure 4: (a) Drawing load, $F_{\mathrm{D}}$ avg, under the steady-state condition; and (b) workpiece surface finish, $R a$, after testing; in the ironing of austenitic stainless steel, AISI 304L.

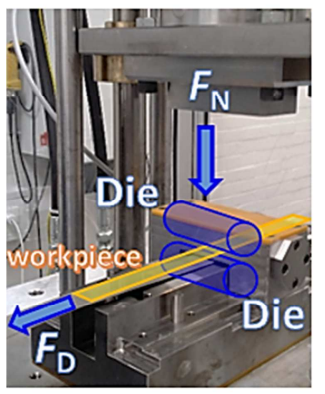

$\square$ Workpiece $\square$ Die
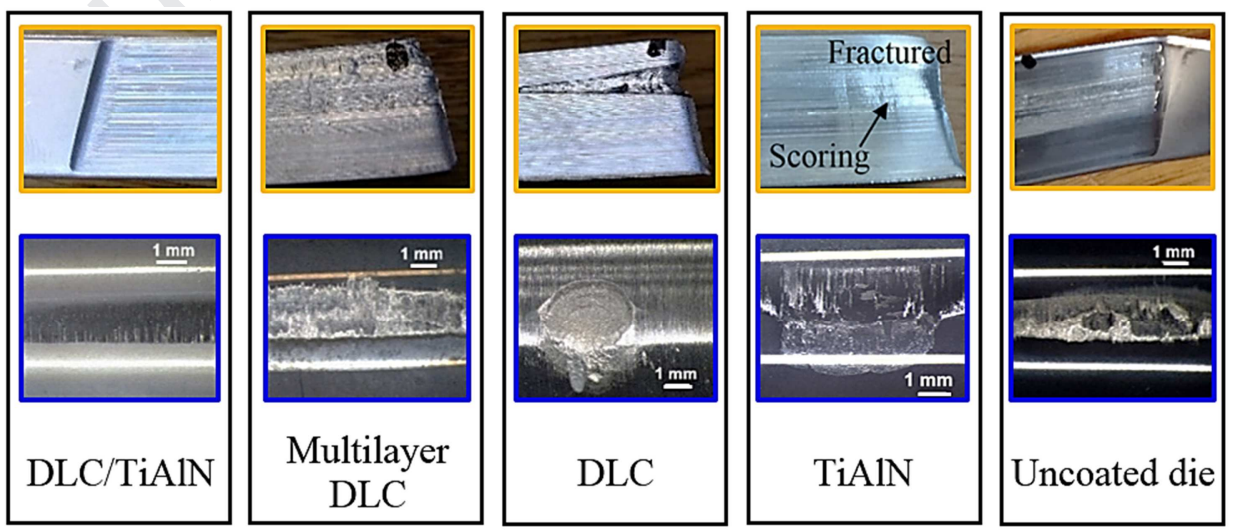

Figure 5: Surface condition of workpiece and dies after testing at temperature $80{ }^{\circ} \mathrm{C}$ under dry friction condition in the ironing of austenitic stainless steel, AISI 304L.

\subsubsection{Long-term performance of the DLC-TiAlN coating in strip-reduction}

Because the DLC/TiAlN coating functioned satisfactorily under all test and lubrication conditions, a long-term experiment utilizing the identical strip-reduction test set- 
up was performed under dry and lubricated conditions. The long-term experiment aimed at examining the durability of the coating according to its resistance to wear. For this experiment, the thickness reduction was $24 \%$, which is more severe than that in the one-time strip-reduction experiment; additionally, the sliding length was $10 \mathrm{~mm}$ per cycle, with a total of 1,500 cycles. This corresponds to a 15-m-long formed workpiece, which is sufficient for an industrial production threshold of 100,000 metal components, as reported by Godi et al. [38]. To evaluate the minimum lubrication in the long-term experiment, $12.8 \mathrm{~g}$ of CR5 lubricant was applied to cover the contact region between the workpiece and the DLC/TiAlNcoated die with a nominal contact area of $900,000 \mathrm{~mm}^{2}$. Thus, the lubrication amount was $14.2 \mathrm{~g} / \mathrm{m}^{2}$ for 1,500 cycles. No wear was observed on the DLC/TiAlN die surface, as shown in Figure 6; moreover, a relatively smooth surface (roughness, $R a$, of 0.14 ) of the formed workpiece was achieved after 1,500 cycles. Although a low formed sheet roughness was obtained in the dry friction lubrication test, the DLC/TiAlN-coated die exhibited slight wear after 1,500 cycles, causing the coating to be peeled off in the contact region. This was due to the repetitive sliding motion in the same contact region, which increased the temperature at the interface between the die and the workpiece surface. This long-term experiment highlights the importance of minimal lubrication for mitigating the macroscopic welding and breaking of microscopic asperities by forming easy-to-shear films that reduce the friction and temperature at the contact region. The results indicate that TiAlN is a good intermediate coating film for bonding DLC and die surfaces; additionally, it can sustain a high, repetitive contact pressure and shear stress in sheet-metal forming.

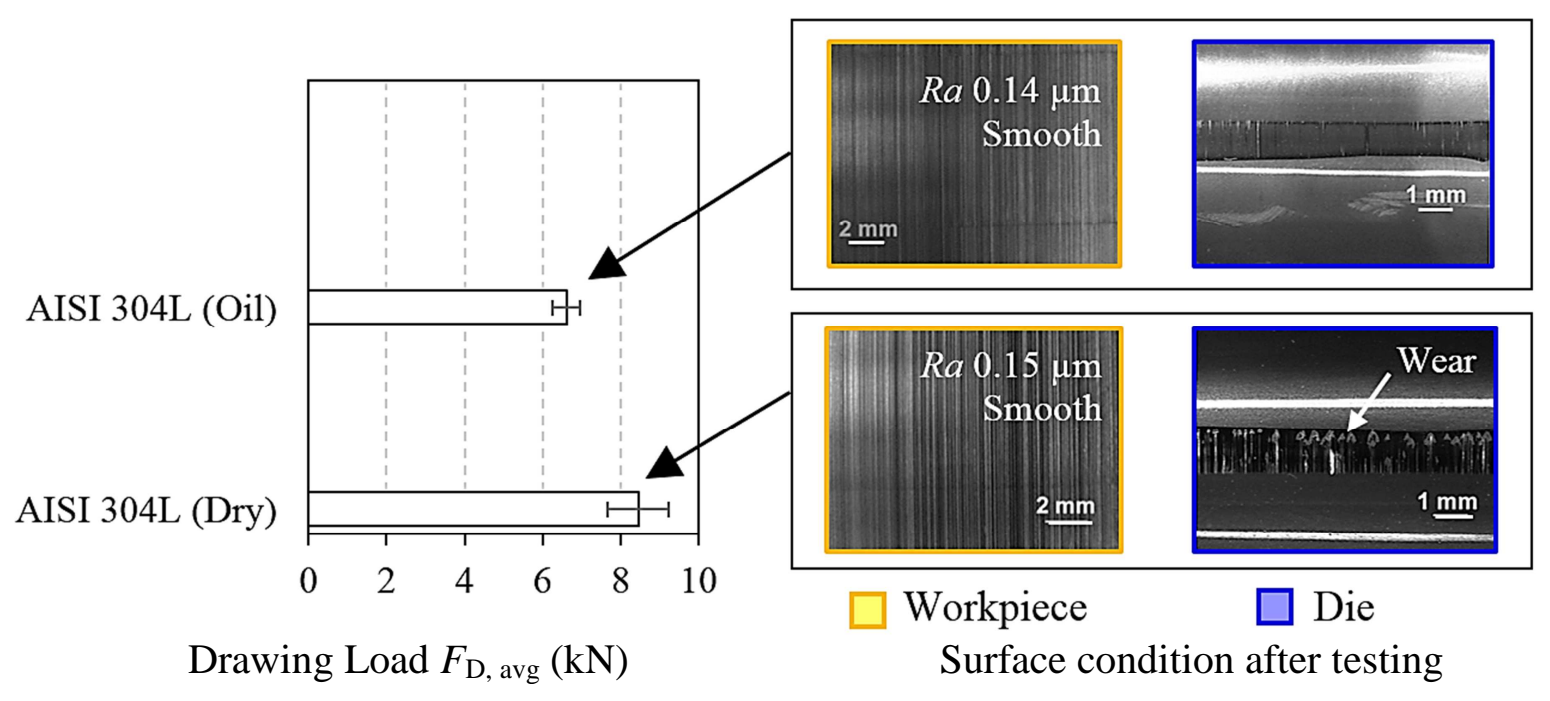




\begin{tabular}{|ll|}
\hline Test parameters used in long-term strip-reduction test: \\
Workpiece $=$ AISI $304 \mathrm{~L}, w 30 \times t 1 \mathrm{~mm}^{2}$ & Sliding length $L=10 \mathrm{~mm}$ per cycle \\
Die diameter $\emptyset_{\mathrm{die}}=15 \mathrm{~mm}$ & Thickness reduction $\Delta t=24 \%$ \\
Sliding speed $v=50 \mathrm{~mm} / \mathrm{s}$ & CR5 oil $\eta=660 \mathrm{cSt}$ \\
\hline
\end{tabular}

Figure 6: Drawing load, $F_{\mathrm{D} \text {,avg, }}$, in the steady-state condition; surface finish, $R a$, after testing; surface condition of the DLC/TiAlN-coated dies in the ironing of austenitic stainless steel, AISI 304L, under long-term test conditions (1,500 cycles).

\subsubsection{Long-term performance of the DLC-TiAlN coating in strip-bending}

Figure 7 shows the effects of a deep-drawing die deposited with the DLC/TiAlN coating on the forming load, torque, surface finish, and wear for high-strength stainless steels. The results refer to the strip-bending test of austenitic stainless steel, AISI 304L, and duplex stainless steel, LDX2101. In the strip-bending test, the high-strength stainless steel strip was drawn around a cylindrical DLC/TiAlN-coated die under constant back tension force of 7,000 $\mathrm{N}$, which corresponds to the back tension stress in the strip of approx. $224 \mathrm{MPa}$. Torque measurement has also been taken into account in the strip-bending test because the torque $T$ is much more sensitive to changes in friction than the drawing load $F_{\mathrm{D}}$ [39]. Further examination of the DLC/TiAlN-coated die in the strip-bending test of austenitic stainless steel, AISI 304L, indicated that DLC/TiAIN can function effectively for up to 1,500 cycles with a low torque and low load in the lubricated condition only. As expected, a worn die surface and a relatively rough formed sheet $(R a=0.37 \mu \mathrm{m})$ were observed in the lubricated condition. The strip-bending test of AISI 304L under the dry friction lubrication condition produced significantly more severe peeling of both the DLC and TiAlN coating films from the die substrate. The strip-bending test of duplex stainless steel, LDX2101, with plain mineral oil without additives (CR5) revealed that the DLC/TiAlN coating experienced severe wear on the die surface, resulting in the slight peeling of the DLC coating layer from the TiAlN coating film in the contact region. This is attributed to the strain-hardening effects of the workpiece materials, which increased the temperature and friction in the die-workpiece contact region. The relatively low formed sheet roughness $(R a=0.26 \mu \mathrm{m})$ and high torque in the experiment indicated strain hardening. Thus, the major difference between the sheet forming of austenitic and duplex stainless steels lies in their mechanical properties. It is difficult for the plain mineral oil to shear off in the contact region, because a good lubricant film containing a special additive, such as an extreme-pressure or anti-wear additive, is necessary. The protective surface films formed by the lubricant can promote easy shearing rather than the welding of the surface asperities of high-strength materials. This indicates that 
the DLC/TiAlN-coated die failed to protect the die surface when the plain mineral oil was applied to the contact region in the forming of the strong materials; extreme-pressure or antiwear additives can mitigate the macroscopic asperities by forming strong protective films.

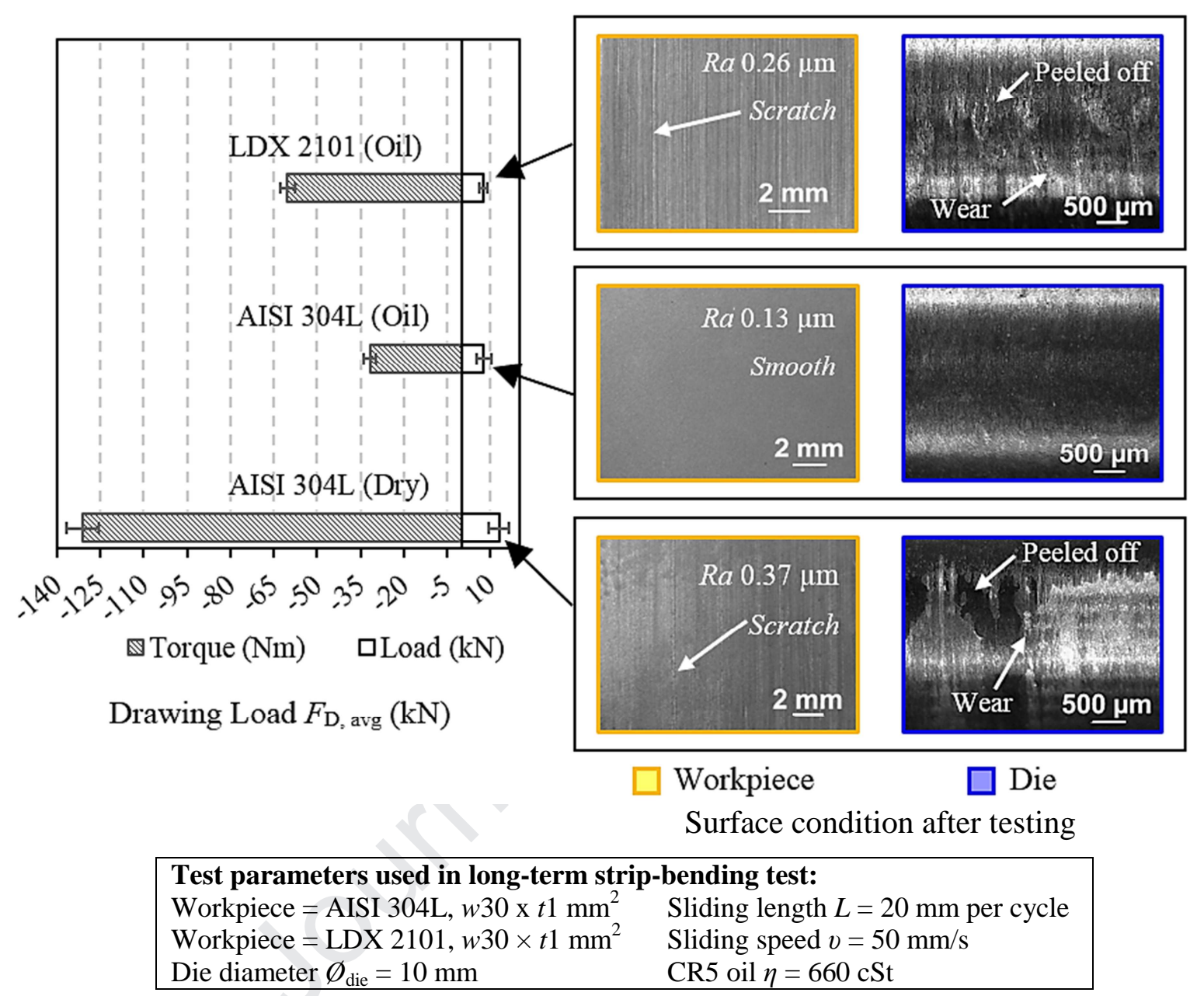

Figure 7: Drawing load, $F_{\mathrm{D} \text {,avg }}$, in the steady-state condition; surface finish, $R a$, after testing; surface condition of DLC/TiAlN-coated dies in deep drawing of austenitic stainless steel, AISI 304L, and duplex stainless steel, LDX 2101, under long-term test conditions $(1,500$ cycles).

\subsection{Effects of die lubrication on friction and interface temperature}

The performance of DLC/TiAlN as a protective coating for the Vanadis 4 substrate can be explained by evaluating the distributions of the contact pressure and temperature in the active contact sliding region between the die and the workpiece surfaces. A numerical simulation combining mechanical and thermal analysis was performed to analyze the pressure and temperature on the active die-workpiece surface. This includes determination of the friction and heat generated at the die-workpiece contact surfaces under dry and lubricated 
conditions. A two-dimensional model of the strip-reduction test of stainless steel, AISI 304L, was created and implemented in LS-DYNA v. R7.1.1 using implicit time integration. To reduce the computation time, only half of the ironing process was modeled; i.e., the plane strain with 1,969 linear quadrilateral elements was meshed for the die and workpiece. A fine, uniform mesh was applied in the contact region between the workpiece and the die surface. The workpiece was treated as an elastic-plastic object of the stainless-steel sheet material, AISI 304L, according to the best-fitted Voce's stress-strain curve shown in Figure 2. The die was modeled as an elastic object. Tables 1 and 4 present the mechanical and thermal properties, respectively, used in the simulation. The heat-transfer coefficient, HTC, between the die and the workpiece surface was assumed to be $40 \mathrm{~kW} / \mathrm{m}^{2} \cdot \mathrm{K}$, in accordance with the thermomechanical simulation of an ironing test performed by Olsson et al. [40]. The initial temperatures of the die and workpiece were both assumed to be $20^{\circ} \mathrm{C}$. The Coulomb friction model was used for the surface contact between the die and the workpiece. The coefficient of friction, $\mu$, was determined by matching experimental and theoretical drawing loads. Figure 8 shows the outcome of the FEM analysis: friction coefficients of $\mu=0.4$ and $\mu=0.2$ for the dry and lubricated conditions, respectively. Figure 9(a) shows the normal pressure distribution in the contact region. The pressure achieved a maximum of 900-1,000 MPa, with no significant difference between the dry and lubricated conditions. Fluctuations in the normal pressure values could be caused by irregular meshes in the die-workpiece contact region. However, as shown in Figure 9(b), a higher temperature at the die-workpiece interface is predicted in the dry condition than in the lubricated one, owing to the higher friction (see Figure 8). The temperature increase $\Delta T$ in the contact region is thus reduced by lubrication; even the plain mineral oil without special additives results in the prevention of wear. The simulation results indicate that the temperature affects the friction of the metal-tometal contact under both the dry and oil-lubricated conditions. A temperature increase can induce oxidation between the die and workpiece surfaces [41], changing the chemical and mechanical properties of the sliding interfaces. Regarding lubrication, a temperature increase reduces the lubricant viscosity, which is typically associated with the temperature-dependent performance reduction $[42,43]$. However, this could cause metal-to-metal contact and thereby increase the friction. This suggests that a careful balance between the lubricant and the coating is necessary for optimizing the performance of the tribological system. 
Table 4: Thermal properties of the test materials in ironing.

\begin{tabular}{lccc}
\hline \multirow{2}{*}{ Components } & \multicolumn{3}{c}{ Thermal properties } \\
\cline { 2 - 4 } & Initial temperature & Heat capacity & Thermal conductivity \\
& $T_{i}\left({ }^{\circ} \mathrm{C}\right)$ & $H[\mathrm{~J} /(\mathrm{kg} \cdot \mathrm{K})]$ & $k[\mathrm{~W} /(\mathrm{m} \cdot \mathrm{K})]$ \\
\hline Die (Vanadis 4) & 20 & 460 & 26 \\
Workpiece (AISI 304L) & 20 & 500 & 15 \\
\hline
\end{tabular}

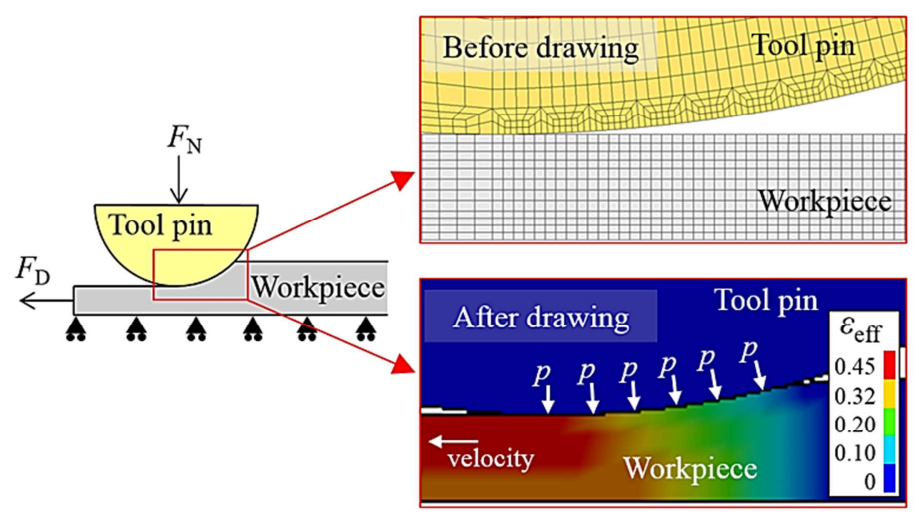

(a)

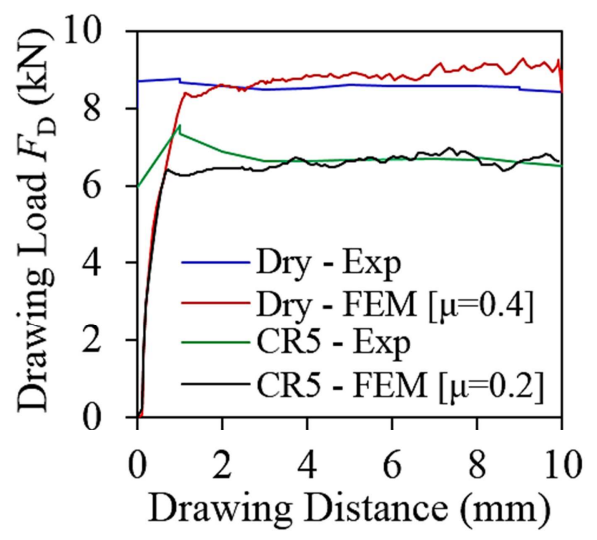

(b)

Figure 8: Drawing load, $F$, with respect to the friction coefficient under the dry and oillubricated conditions.

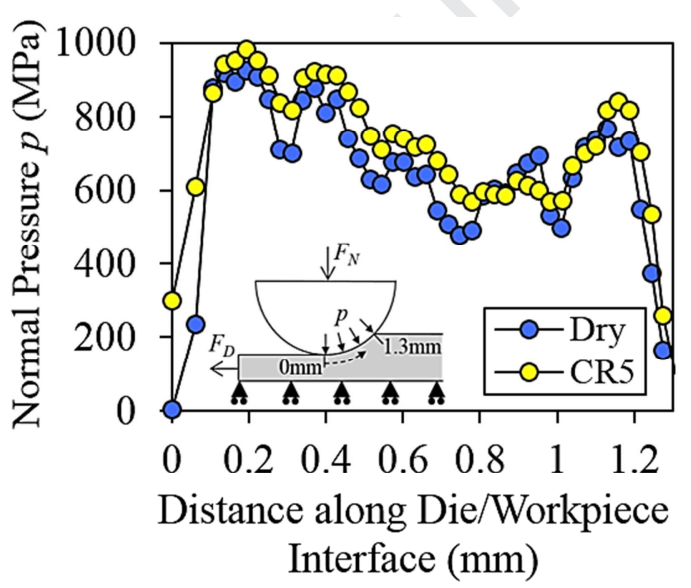

(a)

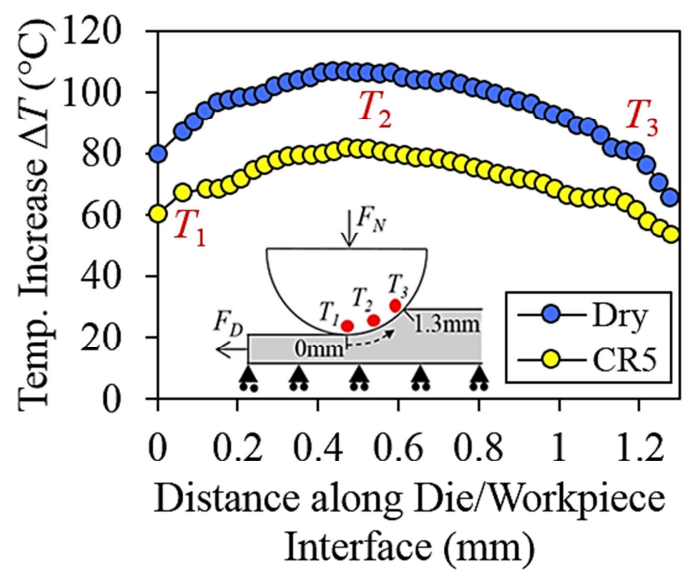

(b)

Figure 9: Distributions of the (a) normal pressure and (b) temperature on the die-workpiece contact surfaces in the ironing simulation.

\subsection{Wear analysis of DLC/TiAIN coated dies under dry lubrication}


Scanning electron micrographs of the DLC/TiAlN-coated die wear track that was tested under the dry lubrication condition in long-term experiments involving strip-reduction and strip-bending tests of stainless steel, AISI 304L, are shown in Figure 10. The delamination of the DLC/TiAlN-coated die in the strip-bending test [Figure 10(b)] is more intense than that in the strip-reduction test [Figure 10(a)]. The wear depth of the ironing die is larger than that of the deep-drawing die, as shown in Figure 10. This suggests that performing a long-term experiment on the DLC/TiAlN-coated die under the dry friction condition is undesirable, as the repetitive sliding at the die-workpiece surface under long-term operation increases the temperature between the sliding surfaces. The resulting high friction can cause progressive loss of the workpiece material to the die surface and subsequently the peeling of the coating, resulting in a damaged coated die surface. To avoid the increase in the interface temperature in the sliding contact region, the minimum quantity of mineral oil with no special additives is used to eliminate the heat generated in the contact region, which prevents direct metal-to-metal interaction and the increase in the friction. As shown in Figure 10(c), the die surface condition after the strip bending of stainless steel indicates the effects of using the plain mineral oil: it reduces the forming load and protects the die surface from adhesive wear (see experimental results shown in Figures 6 and 7). The experimental results indicate that the combination of the low-friction DLC coating and the minimum quantity of mineral oil with no special additives is advantageous for reducing the metal-to-metal contact interaction and the friction generated in the contact region. It is also beneficial for producing a smooth formed steel surface $R a$ value lower than the initial workpiece roughness, $R a=0.2 \mu \mathrm{m}$.

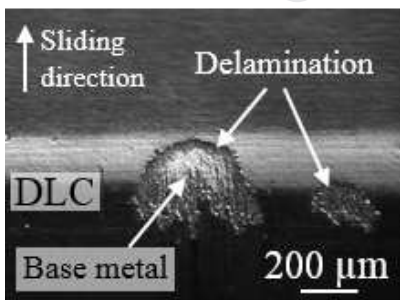

(a)

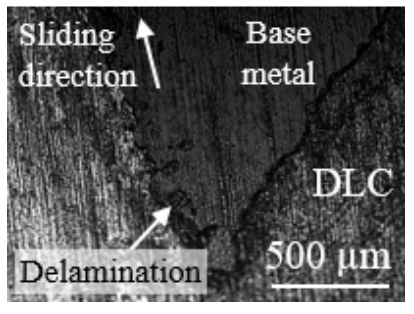

(b)

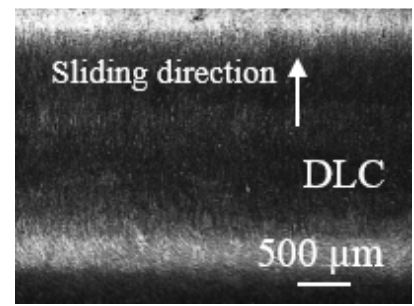

(c)

Figure 10: SEM micrographs of the die surface condition after 1,500 cycles under the dry friction condition for the (a) strip-reduction and (b) strip-bending tests as well as (c) under the oil-lubricated condition for the strip-bending test.

\subsection{Microstructural analysis of DLC/TiAIN coating}


The improved wear resistance of the DLC/TiAlN as a protective coating for the Vanadis 4 substrate can be explained by examining the microstructure and elemental compositions of DLC/TiAlN coating. Figure 11 shows a cross-sectional view of the DLC/TiAlN coating. The DLC film (top layer) and TiAlN film (bottom layer) form the coating over the substrate (tool steel Vanadis 4). Further study of the morphology of each DLC/TiAlN coating layer revealed that the thicknesses of the DLC and TiAlN coating films were 2.4 and $2 \mu \mathrm{m}$, respectively. The SEM images display that the TiAlN film (intermediate layer) is bonded perfectly with the DLC coating film (top layer) and the Vanadis 4 substrate (bottom layer). This is because the $\mathrm{Cr}$ interlayer, as indicated by the EDX results in Figure 12 (top), release the stress gradient at the interface between the DLC and TiAlN coating films [44]. The EDX results also indicate that the use of the elements, $\mathrm{Cr}$ and $\mathrm{Ti}$, in the DLC/TiAlN coating improved the adhesion strength, producing low energy at the interface, a strong and stable chemical bond, and a low stress gradient at the interface [35-37]. The first DLC layer exhibits a clustered and rough structure, which differs from the fine and smooth morphology of the TiAlN layer. The large columnar grain structure of the $\mathrm{CrCN} / \mathrm{CrN}$ interlayer under the first DLC layer could explain the good adhesion of the DLC/TiAlN coating $[31,38]$. The dense microstructure of the TiAlN coating possesses a uniform columnar structure with few pores and inclusions, as shown in Figure 11 (bottom right). The high Al content in the TiAlN coating, as shown in Figure 12 (middle), increases the hardness of the DLC/TiAlN coating. This suggests that the TiAlN interlayer is vulnerable to shear stress to improve the adhesion strength between the DLC film and the Vanadis 4 substrate, as the $\mathrm{Cr}$ interlayer improves the adhesion strength by reducing the stress gradient between the TiAlN and the DLC coating films. Thus, the combined effects could reduce the sliding-originated surface tensile stresses of the DLC/TiAlN coating, preventing severe wear and extending the die lifetime.

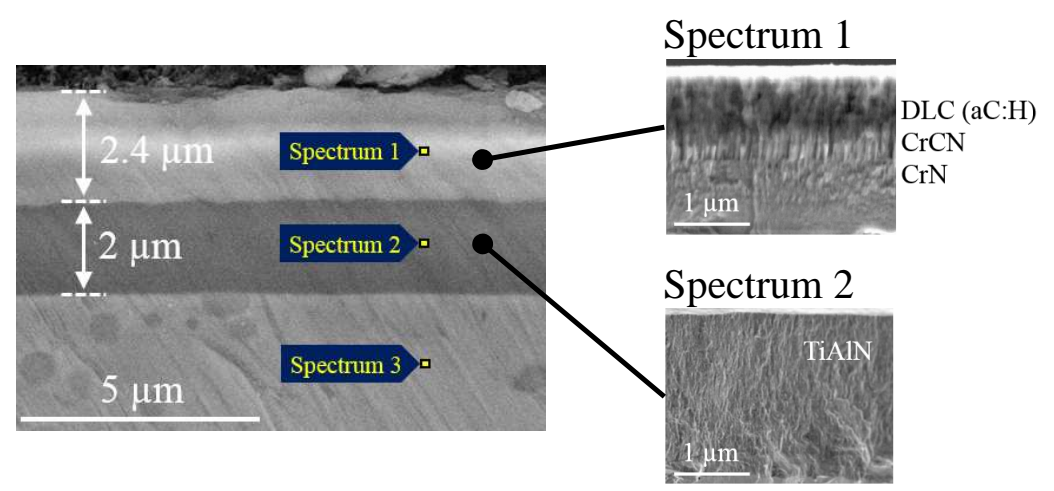


Figure 11: Cross-sectional images of the DLC/TiAlN coatings deposited on the tool steel, Vanadis 4 (Spectrum 1, DLC; Spectrum 2, TiAlN; Spectrum 3, Vanadis 4).

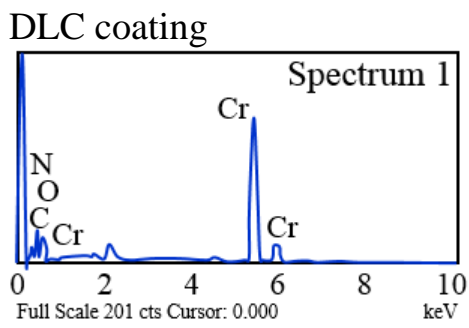

\begin{tabular}{ccc}
\hline Element & Weight $\%$ & Atomic\% \\
\hline $\mathrm{Cr}$ & 73.54 & 41.92 \\
$\mathrm{~N}$ & 13.88 & 29.38 \\
$\mathrm{C}$ & 8.77 & 21.63 \\
$\mathrm{O}$ & 3.81 & 7.07 \\
\hline
\end{tabular}

TiAlN coating

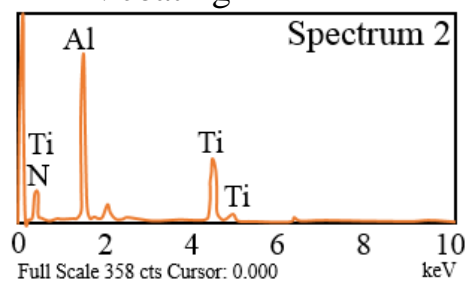

\begin{tabular}{ccc}
\hline Element & Weight\% & Atomic\% \\
\hline $\mathrm{Ti}$ & 45.01 & 24.80 \\
$\mathrm{Al}$ & 31.33 & 30.64 \\
$\mathrm{~N}$ & 23.65 & 44.56 \\
\hline
\end{tabular}

Tool steel, Vanadis 4

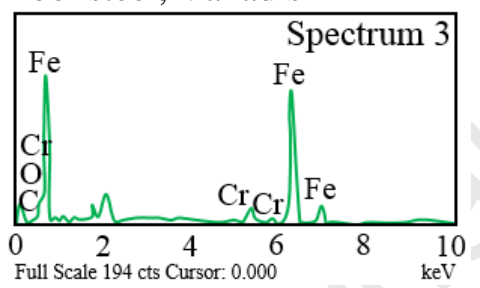

\begin{tabular}{ccc}
\hline Element & Weight $\%$ & Atomic\% \\
\hline $\mathrm{Fe}$ & 87.82 & 72.08 \\
$\mathrm{Cr}$ & 5.16 & 4.55 \\
$\mathrm{O}$ & 3.57 & 10.22 \\
$\mathrm{C}$ & 3.45 & 13.15 \\
\hline
\end{tabular}

Figure 12: Elemental compositions of the DLC/TiAlN die coating according to SEM-EDX.

\section{Conclusion}

The effectiveness of the DLC/TiAlN as a protective coating on the die surface was evaluated using simulative laboratory tests, i.e., strip-reduction and strip-bending tests. The performance of the DLC/TiAlN-coated die under oil and dry lubrication conditions was comprehensively evaluated through load measurement, surface roughness measurement, as well as hardness and microstructure examination. The following conclusions can be drawn.

- The DLC/TiAlN exhibits a high potential protective coating under all test conditions. The screening test, utilizing single-stroke strip-reduction testing, has produced no indication of peeling of the DLC/TiAlN coating under both dry and oil-lubricated conditions. However, slight peeling of the DLC/TiAlN coating from the tool steel substrate is visible in longterm sheet-forming operation. 
- Adhesive wear was determined to be the primary reason for galling in sheet-forming of stainless steels under dry friction condition. Utilizing the combination of plain mineral oil and the DLC/TiAlN coating in the long-term strip-reduction testing has demonstrated that the combination is a good tribological system that promotes the reduction of the friction and wear, thereby extending the die service life. This suggests that the sheet-forming of stainless steels utilizing the available hazardous chlorinated paraffin oil can be replaced with the environmentally friendly oil for a more sustainable future and safe working environment, provided that the DLC/TiAlN coating is required.

- The thermo-mechanical numerical simulation supported the experimental results, in which the lubricant eliminates the heat generated in the active contact region between the die and the workpiece surfaces. However, the dry friction condition is undesirable due to the direct metal-to-metal interaction and the increase in the interface temperature in the active contact region. This suggest that a careful balance between the lubricant and the coating is required for optimizing the performance of the tribological system.

- The long-term sheet-forming of stainless steel revealed that the DLC/TiAlN coating protects the die surface from the onset of lubricant-film breakdown, even under the dry friction lubrication condition. This could be due to a large amount of titanium in the interlayer TiAlN. This supports that the interlayer TiAlN coating enhanced the DLC coating system performance. Interestingly, the columnar grain structure of the $\mathrm{CrCN} / \mathrm{CrN}$ interlayer under the first DLC layer further improved the adhesion strength of the DLC/TiAlN to improve the tool lifetime under all test conditions.

\section{Acknowledgments}

This work was financially supported by the Danish Council for Independent Research [grant number DFF-4005-00130] and the Taiho Kogyo Tribology Research Foundation [grant number 9008-00015]. The authors gratefully acknowledge support from the Universiti Malaysia Perlis (UniMAP) and the Technical University of Denmark (DTU).

\section{References}

[1] B. Kilinc, O. Cegil, S. Sen, U. Sen, Wear behavior of TiAlN and CrAlN coatings deposited by TRD Process on AISI D2 Steel, Acta Phys. Pol. A. 125 (2014) 362-364. doi:10.12693/APhysPolA.125.362.

[2] K. Bobzin, E. Lugscheider, R. Nickel, N. Bagcivan, A. Krämer, Wear behavior of 
Cr1-xAlxN PVD-coatings in dry running conditions, Wear. 263 (2007) 1274-1280. doi:10.1016/j.wear.2007.01.118.

[3] N. Bay, A. Azushima, P. Groche, I. Ishibashi, M. Merklein, M. Morishita, T. Nakamura, S. Schmid, M. Yoshida, Environmentally benign tribo-systems for metal forming, CIRP Ann. - Manuf. Technol. 59 (2010) 760-780. doi:10.1016/j.cirp.2010.05.007.

[4] F. Klocke, T. Maßmann, K. Gerschwiler, Combination of PVD tool coatings and biodegradable lubricants in metal forming and machining, Wear. 259 (2005) 11971206. doi:10.1016/j.wear.2005.01.041.

[5] H. Kim, S. Han, Q. Yan, T. Altan, Evaluation of tool materials, coatings and lubricants in forming galvanized advanced high strength steels (AHSS), CIRP Ann. - Manuf. Technol. 57 (2008) 299-304. doi:10.1016/j.cirp.2008.03.029.

[6] C.H. Shoba, D. Siva Prasad, Cathodic arc TiAlN PVD coatings for machining applications, Mater. Sci. Indian J. 12 (2016) 142-146.

[7] M. Prieske, H. Hasselbruch, A. Mehner, F. Vollertsen, B. Bremer, K. Str, Friction and wear performance of different carbon coatings for use in dry aluminium forming processes, Surf. Coat. Technol. $357 \quad$ (2019) 1048-1059. doi:10.1016/j.surfcoat.2018.10.103.

[8] A. Liu, J. Deng, H. Cui, Y. Chen, J. Zhao, Friction and wear properties of TiN, TiAlN, AlTiN and CrAlN PVD nitride coatings, Int. J. Refract. Met. Hard Mater. 31 (2012) 82-88. doi:10.1016/j.ijrmhm.2011.09.010.

[9] N. Norrby, M.P. Johansson-Jõesaar, M. Odén, Improved metal cutting performance with bias-modulated textured Ti0.50A10.50N multilayers, Surf. Coatings Technol. 257 (2014) 102-107. doi:10.1016/j.surfcoat.2014.05.045.

[10] P.H. Mayrhofer, A. Hörling, L. Karlsson, J. Sjölén, T. Larsson, C. Mitterer, L. Hultman, Self-organized nanostructures in the Ti-Al-N system, Appl. Phys. Lett. 83 (2003) 2049-2051. doi:10.1063/1.1608464.

[11] J. Hardell, B. Prakash, Tribological performance of surface engineered tool steel at elevated temperatures, Int. J. Refract. Met. Hard Mater. 28 (2010) 106-114. doi:10.1016/j.ijrmhm.2009.07.009.

[12] M. Darsin, T. Pasang, Z. Chen, Performance of TiAlN PVD coated carbide drill when drilling titanium 6246 alloy, in: MATEC Web Conf., 2017: pp. 1-8.

[13] S.S. Gill, J. Singh, H. Singh, R. Singh, Investigation on wear behaviour of cryogenically treated TiAlN coated tungsten carbide inserts in turning, Int. J. Mach. 
Tools Manuf. 51 (2011) 25-33. doi:10.1016/j.ijmachtools.2010.10.003.

[14] J.M. Castanho, M.T. Vieira, Effect of ductile layers in mechanical behaviour of TiAlN thin coatings, J. Mater. Pro. 143-144 (2003) 352-357. doi:10.1016/S09240136(03)00454-0.

[15] M. Nouari, H. Makich, On the physics of machining titanium alloys: Interactions between cutting parameters, microstructure and tool wear, Metals (Basel). 4 (2014) 335-358. doi:10.3390/met4030335.

[16] Z. Hao, D. Gao, Y. Fan, R. Han, New observations on tool wear mechanism in dry machining Inconel718, Int. J. Mach. Tools Manuf. 51 (2011) 973-979. doi:10.1016/j.ijmachtools.2011.08.018.

[17] S.K. Khrais, Y.J. Lin, Wear mechanisms and tool performance of TiAlN PVD coated inserts during machining of AISI 4140 steel, Wear. 262 (2007) 64-69. doi:10.1016/j.wear.2006.03.052.

[18] C.R.K. Kumar, P.K. Nair, B. Ramamoorthy, Performance of TiCN and TiAlN tools in machining hardened steel under dry, wet and minimum fluid application, Int. J. Mach. Mach. Mater. 3 (2008) 133-142. doi:10.1504/IJMMM.2008.017630.

[19] N. Andriya, P.V. Rao, S. Ghosh, Dry machining of Ti-6Al-4V using PVD coated TiAlN tools, in: Proc. World Congr. Eng., 2012: pp. 2-7.

[20] G. Cueva, A. Sinatora, W.L. Guesser, A.P. Tschiptschin, Wear resistance of cast irons used in brake disc rotors, Wear. 255 (2003) 1256-1260. doi:10.1016/S00431648(03)00146-7.

[21] L.A. Dobrzański, L.W. Zukowska, J. Mikuła, K. Gołombek, D. Pakuła, M. Pancielejko, Structure and mechanical properties of gradient PVD coatings, J. Mater. Process. Technol. 201 (2008) 310-314. doi:10.1016/j.jmatprotec.2007.11.283.

[22] J.S. Koehler, Attempt to design a strong solid, Phys. Rev. B. 2 (1970) 547-551. doi:10.1103/PhysRevB.2.547.

[23] Y. Hu, L. Li, X. Cai, Q. Chen, P.K. Chu, Mechanical and tribological properties of TiC/amorphous hydrogenated carbon composite coatings fabricated by DC magnetron sputtering with and without sample bias, Diam. Relat. Mater. 16 (2007) 181-186. doi:10.1016/j.diamond.2006.05.010.

[24] M.X. Wang, J.J. Zhang, J. Yang, L.Q. Wang, D.J. Li, Influence of Ar/N2 flow ratio on structure and properties of nanoscale ZrN/WN multilayered coatings, Surf. Coatings Technol. 201 (2007) 5472-5476. doi:10.1016/j.surfcoat.2006.07.015.

[25] L. Du, S. Wang, Y. Du, L. Qiu, Z. Chen, X. Chen, Z.K. Liu, C. Zhang, Deposition of 
CVD-TiCN and TiAlN coatings guided with thermodynamic calculations, Int. J. Mater. Res. 109 (2018) 277-283. doi:10.3139/146.111613.

[26] F. Klocke, T. Krieg, Coated tools for metal cutting - Features and applications, CIRP Ann. - Manuf. Technol. 48 (1999) 515-525. doi:10.1016/S0007-8506(07)63231-4.

[27] I.Y. Konyashin, Improvements in reliability and serviceability of cemented carbides with wear-resistant coatings, Mater. Sci. Eng. A. 230 (1997) 213-220. doi:https://doi.org/10.1016/S0921-5093(96)10794-2.

[28] H. Derflinger, V., Brandle, H. and Zimmermann, New hard/lubricant coating for dry machining, Surf. Coatings Technol. $113 \quad$ (1999) 286-292. doi:https://doi.org/10.1016/S0257-8972(99)00004-3.

[29] P.E. Hovsepiana, Q. Luoa, G. Robinsona, M. Pittmana, M. Howartha, D. Doerwaldb, R. Tietemab, W.M. Simc, A. Deemingd, T. Zeus, TiAlN/VN superlattice structured PVD coatings: A new alternative in machining of aluminium alloys for aerospace and automotive components, Surf. Coatings Technol. 201 (2006) 265-272. doi:10.1016/j.surfcoat.2005.11.106.

[30] A. Biksa, K. Yamamoto, G. Dosbaeva, S.C. Veldhuis, G.S. Fox-Rabinovich, A. Elfizy, T. Wagg, L.S. Shuster, Wear behavior of adaptive nano-multilayered AlTiN/MexN PVD coatings during machining of aerospace alloys, Tribol. Int. 43 (2010) 1491-1499. doi:10.1016/j.triboint.2010.02.008.

[31] M.H. Sulaiman, P. Christiansen, N. Bay, A study of DLC coatings for ironing of stainless steel, IOP Conf. Ser. J. Phys. 896 (2017) 1-7.

[32] M.H. Sulaiman, P. Christiansen, N. Bay, A study of anti-seizure tool coatings for ironing of stainless steel, J. Tribol. - Spec. Issue WTC2017. 17 (2017) 1-11.

[33] Assab steels Vanadis 4 cold work steel, Mater. Prop. Data. (2018). http://www.matweb.com/search/datasheet.aspx?matguid=b08b84d722724503b1f80c43 8ec68cbd\&ckck=1 (accessed January 20, 2019).

[34] Outokumpu AISI 304L Cr-Ni austenitic stainless steel, Mater. Prop. Data. (2018). http://www.matweb.com/search/DataSheet.aspx?MatGUID=1118437e4dc845dcadc5a 1c6762cba7f (accessed January 20, 2019).

[35] M. Arentoft, N. Bay, P.T. Tang, J.D. Jensen, A new lubricant carrier for metal forming, CIRP Ann. - Manuf. Technol. $58 \quad$ (2009) 243-246. doi:10.1016/j.cirp.2009.03.062.

[36] N. Bay, D.D. Olsson, J.L. Andreasen, Lubricant test methods for sheet metal forming, Tribol. Int. 41 (2008) 844-853. doi:10.1016/j.triboint.2007.11.017. 
[37] M.H. Sulaiman, P. Christiansen, N. Bay, The influence of tool texture on friction and lubrication in strip reduction testing, Lubricants. 5 (2017) 1-11. doi:10.3390/lubricants5010003.

[38] A. Godi, J. Grønbæk, L. De Chiffre, Characterisation and full-scale production testing of multifunctional surfaces for deep drawing applications, CIRP J. Manuf. Sci. Technol. 16 (2015) 64-71. doi:10.1016/j.cirpj.2016.07.001.

[39] J.L. Andreasen, D.D. Olsson, K. Chodnikiewicz, N. Bay, Bending under tension test with direct friction measurement, Proc. Inst. Mech. Eng. Part B J. Eng. Manuf. 220 (2006) 73-80. doi:10.1243/095440505X32913.

[40] D.D. Olsson, N. Bay, J.L. Andreasen, Prediction of limits of lubrication in strip reduction testing, CIRP Ann. - Manuf. Technol. 53 (2004) 231-234. doi:10.1016/S0007-8506(07)60686-6.

[41] S.M. Hsu, R.S. Gates, Boundary lubricating films: Formation and lubrication mechanism, Tribol. Int. 38 (2005) 305-312. doi:10.1016/j.triboint.2004.08.021.

[42] S.M. Hafis, M.J.M. Ridzuan, R.N. Farahana, A. Ayob, S. Syahrullail, Paraffinic mineral oil lubrication for cold forward extrusion: Effect of lubricant quantity and friction, Tribol. Int. 60 (2013). doi:10.1016/j.triboint.2012.10.014.

[43] S.M. Hafis, M.J.M. Ridzuan, A.R. Mohamed, R.N. Farahana, Finite element and experimental study of friction and lubricants in strip drawing, 2014. doi:10.4028/www.scientific.net/AMM.554.345.

[44] K.S. Kim, H.K. Kim, J.H. La, S.Y. Lee, Effects of interlayer thickness and the substrate material on the adhesion properties of CrZrN coatings, Jpn. J. Appl. Phys. 55 (2016) 01AA02. doi:10.7567/JJAP.55.01AA02.

[45] P. Carlsson, M. Olsson, PVD coatings for sheet metal forming processes - A tribological evaluation, Surf. Coatings Technol. $200 \quad$ (2006) 4654-4663. doi:10.1016/j.surfcoat.2004.10.127. 


\section{Highlights:}

- Ironing and deep drawing tests performed under different tribological conditions

- DLC/TiAlN coating resists galling under dry friction and thin film lubrication

- DLC/TiAlN utilized more environment-friendly oils than chlorinated paraffin oil

- TiAlN interlayer coating enhanced DLC performance 